\title{
COMPORTAMENTO DE DIVER SAS PLANT AS DANINHAS, DE OCORRÊNCIA COMUM NO ESTADO DE SÃO PAULO, EM RELAÇÃO A DUAS ESPÉCIES DE NEMATÓIDES DAS GALHAS: SEGUNDA PARTE
}

\author{
L.C.C.B. FERRAZ 1
}

1

ESALQ-USP - Piracicaba -

Departamento de Zoologia.

\section{RESU MO}

Estudou-se o comportamento de dez espécies de plantas daninhas, comuns no Estado de São Paulo, quan do o solo em que vegetavam foi inoculado com os nematóides das galhas Meloigodyne iavanica (raça 4) ou M. javanica. As avaliações foram feitas 50 dias após a inoculação dos parasitos, baseando-se nos números de galhas e ootecas presentes nas raízes e nos valores de altura e de pesos secos da parte aérea e siste mas radiculares das plantas. Em relação às duas espécies de nematóides, comportaram-se como muito resistentes Brachiaria plantaginea, Cenchrus echinatus, Digitaria horizontalis e Eleusine indica. Cassia occidentalis, Cassia tora e Indigofera truxillensis mostraram baix a suscetibilidade enquanto Hyptis lophanta foi moderadamente suscetível. Leonotis nepetaefolia foi altamente suscetível e Echinochloa colonum toler ante aos parasitos.

PALAVRAS-CHAVE: plantas daninhas hospedeiras; Meloidogyne.

\section{SUMMARY}

The behaviour of ten different weed species belonging to Gramineae, Labiatae and Leguminosae in relation to the root-knot nematodes Meloidogyne incognita (race 4) and $M$. javanica was studied under greenhouse conditions. Evaluations were carried out 50 days after nematode inoculations $(28,000$ eggs/plant) by means of gall andegg masses indexes observed in the root systems and through the determination of height and/or top dry weight of the plants.Branquiaria plantaginea, Cenchrus echinatus, Digitaria horizontalis and Eleusine indica were very unfavourable hosts for the parasites, whereas Cassia occidentalis, Cassia tora and Indigofera truxillensis showed low suscetibility and Hyitis lophanta was moderately susceptible. Leonotis nepetaefolia was highly suscetible and Echinochloa colonum tolerant to the parasites.

KEY-WORDS; weed hosts; root-knot nematodes. 


\section{INTRO DUÇÃO}

As plantas daninhas podem servir de hospedeiros alternativos a importantes fitonematóides assegurando-lhes a sobrevivência e reprodução em suas raízes, o que limita a eficiência de certas medidas de controle, como a rotação de culturas.

No Brasil, já existem diversos relatos de associações entre plantas daninhas e nema tóides fitoparasitos, particularmente os pertencentes ao gênero Meloidogyne (nematóides das galhas), sumarizad os por Ferraz et al. (1983).

$\mathrm{O}$ presente trabalho representa a segunda parte de um estudo conduzido pelo autor sobre o comportamento de virias plantas daninhas, comuns nos solos paulistas, em relação as espécies Meloidogyne incognita (raça 4) e $M$. iavanica, verificando-se, como na primeira parte (Ferraz, 1985), os graus de infes tação dos parasitos e sua possível interferência no crescimento das plantas.

\section{MATERIAL E MÉTODOS}

As plantas daninha sutilizadas no trabalho foram as seguintes, apresentadas segundo a posição sistemática e nomes populares propostos por Lorenzi (1982): Graminea Branchiaria plantaginea (Link.) Hitch. (capim-marmelada), Cenchrus echinatus L. (capim-carrapicho), Digitaria horizontalis Willd. (capim-colchão), Echinochloa colonum Link. (capim - arroz) e Eleusine indica (L.) Gaertn. (capim pé-de-galinha); Labiatae Hyptis lophanta Mart. ex Benth. (fazendeiro) e Leonotis nepetaefolia (L.) R. Br. (cordão-defrade); Leguminosae - Cassia occidentalis L. (fedegoso), Cassia tora L. (fedego so) e Indigofera truxillensis H.B. K. (anileira).

$\mathrm{O}$ delineamento experimental e as metodologias referentes às inoculações dos nematóídes, avaliações das infestações e analise do comportamento das plantas ora testadas foram semelhantes aos adotados e descritos na primeira parte do estudo (Ferraz, 1985).

No presente trabalho foram calculados os coeficientes de correlação entre os valores atribuídos às plantas daninhas pelos 3 métodos de avaliação do grau de infestação das raízes utilizadas, ou seja, número de galhas (método 1) x número de ootecas (método 3) e porcentagem do sistema radicular ocupado por galhas (método 2) $\mathrm{x}$ número de ootecas (método 3). Para tanto, consideraram-se as dez espécies de plantas ora analisadas e também as dez incluídas na primeira parte do estudo.

\section{RESULTADOS E DISCUSSÃO}

Os resultados obtidos (valores médios de 7 repetições) para grau de infestação dos sistemas radiculares pelos 3 métodos de avaliaço, pesos secos da parte aérea e das raízes, altura das plantas e número de larvas por $10 \mathrm{~g}$ de raízes estão apresentados no Quadro 1.

Observa-se que ocorreram desde plantas daninhas altamente suscetíveis até muito resistentes, além de uma espécie tolerante.

Entre as gramíneas estudadas, todas mostraram alta resistência aos nema tóides, exce to o capi m-arroz.

O capim-carrapicho (C. echinatus) mostrou-se hospedeiro to talmente desfavorável aos parasitos, 
Quadro 1. Valores médios (7 repetiçōes) de grau de infestação dos sistemas radiculares, avaliạ dos por 3 diferentes métodos, pesos secos da parte aérea e das raízes (em gramas), al tura das plantas (em centímetros) e $\mathrm{n}$ Q de larvas por $10 \mathrm{~g}$ de raízes determinados para as espécies daninhas estudadas.

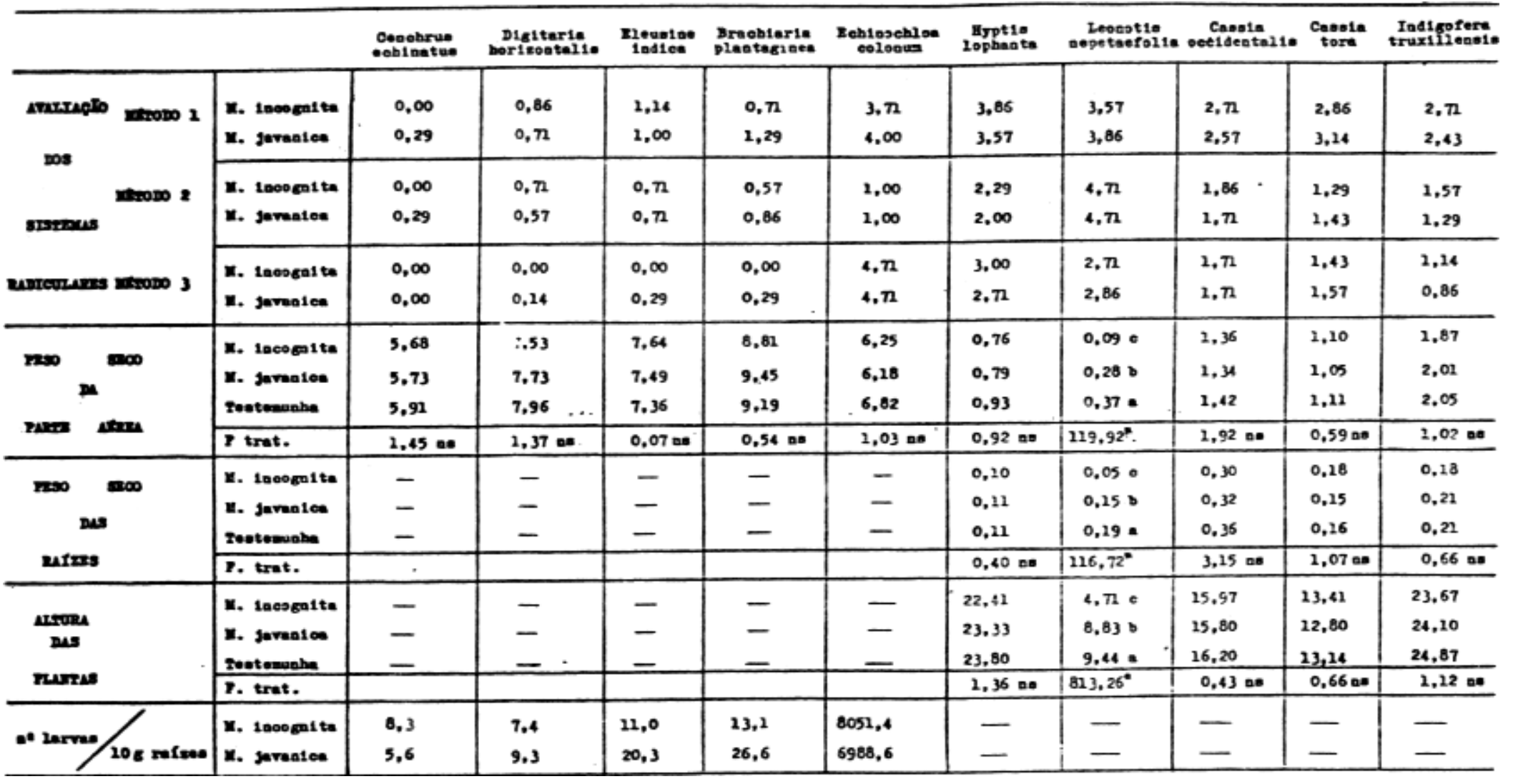


não se encontrando nenhuma ooteca e apenas raras galhas nos sistemas radiculares inoculados.

Os capins colchão (D. horizontalis L) e pé-de-galinha (Eleusine indica) sofreram infestações muito leves das duas espécies de nematóides, observando-se galhas esparsas e ootecas ocasionais. As galhas só eram bem visíveis ao estereoscópio e em seu interior ocorriam geralmente larvas infestantes ou parasitas ("salsichas"). As poucas fêmeas maduras encontradas estavam com a maior parte do corpo exposta fora das raízes. Não ocorreram diferenças entre as plantas dos diferentes tratamentos em relação ao crescimento e os números de larvas determinados por $10 \mathrm{~g}$ de raízes em ambas as espécies foram muito baixos, considerando-se os dois capins como hospedeiros desfavorá veis aos parasitos inoculados.

O capim-marmela da (B. plantaginea) também sofreu infestações leves ou muito leves, encontrando-se-algumas galhas esparsas e apenas duas ootecas, formadas por $M$. javanica. As galhas e as fêmeas observadas tinham as mesmas características já mencionadas para os capins colchao e pé-de-galinha. Como não ocorreram diferenças entre os tratamentos quanto ao crescimento das plantas, considerou-se também o capim-marmela da como muito resistente ou desfavorável aos nematóides em estudo. Comportamen to semelhante foi verificado por Antonio \& Dall'Agnol (1983) em experimento conduzido no Estado do Paraná. No entanto, Zem \& Lordello (1976) tiveram a oportunidade de observar investação severa de $M$. incognita e $M$. javanica em raízes da gramínea em questão, durante exame de amostras procedentes de Amambaí (MT), documentando o relato com fotografias. Os siste- mas radiculares parasitados exibiam áreas necróticas e galhas muito evidentes na região apical das radicelas, sinto mas não observados no presente trabalho e no de Antonio \& Dall'Agnol. Entre as possíveis explicações para a discrepância apontada pode-se lembrar a existência de raças, com diferentes c cír culos de hospedeir os, dentro das espécies de nematóides das galhas, ou especular sobre uma alteração no comportamento da planta daninha, no caso do material severamente infestado, com quebra de resistência provocada pela ocorrência de temperaturas muito elevadas no ambiente. Vale acrescentar, na ausência de outros registros de meloidoginose em B. plantaginea, que Ponte et al. (1982) estudaram o comportamento de quatro outras espécies de Brachiaria em relação a $M$. incognita e $M$. javanica considera ndo-as praticamente imunes a esses nematóides. Em vista do exposto, opina o autor por confirmar, pelo menos por ora, o capimmarmelada como hospedeiro desfavorável aos parasitos inoculados, considerando o relato de Zem \& Lordel lo suficientemente importante para justificar o prosseguimento das observações até o esclarecimento definitivo do assunto.

Nas raízes do capim-arroz (E. colonum), ao contrário das demais gramíneas, encontram-se numerosas galhas e ootecas, o que pode ser verificado atra vés das notas atribuídas pelos métodos 1 e 3 . Entretanto, como nos capins anteriores, as galhas forma das no capim-arro $\mathrm{z}$

apenas eram visíveis com segurança ao estereoscópio e, embora frequentes, ocupavam pequena porcentagem dos sistemas radiculares, pois estes eram muito ricos em radicelas. Por essa razão, as notas atribuídas pelo método 2 foram bem in- 
feriores às do método 1 . Os números de ovos e larvas obtidos por $10 \mathrm{~g}$ de raízes mostraram ter ocorrido intensa infestação e aumento populacional dos parasitos. Como não se observaram diferenças significativas no crescimento das plantas, o capim-arroz foi considera do tolerante aos nematóides inoculados, atuando como hospedeiro favorável e suportando bem seus ataques, ainda que severos. Relatos de meloidoginose em E. colum eram conhecidos do Sudão (Yassin \& Zeidan, 1982) e Zimbabwe (Martin, 1958), sendo as infestações modera das e caracterizadas pela presença de minúsculos engros samentos radicu lares.

$\mathrm{O}$ fazendeiro, $H$. lophanta foi parasitado pelas duas espécies de nematói des, observando-sevariação nos graus de infestação das raízes em função dos diferentes métodos de avaliação e predominância de ataques considerados moderados. As galhas eram bem visíveis e as ootecas externas. Não ocorreram diferenças relativamente ao crescimento das plantas, ficando os sintomas da meloidoginose restritos aos sistemas radiculares. A planta daninha em pauta foi considerada moderadamente suscetível aos nematóides, isto é, hospedeiro capaz de assegurar, alternativamente, a sobrevivência dos nematóides na área, sem concorrer decisi vamente ao aumento de suas popula ções.

O exame dos sistemas radiculares de $L$. nepetafolia, o cordã o de-frade, mostrou ter ocorrido intenso parasitismo de ambos os nematóides, preponderando infestações tidas como severas pelo método 1 e muito severas pelo método 2. As galhas eram muito evidentes e ocorriam também nas raízes mais grossas, ocupando a maior parte dos sistemas radiculares. As oote- cas eram externas e internas,e, embora menos numerosas que as galhas, suficientes para evidenciar a suscetibilidade do hospedeiro. As plantas do tratamento testemunha apresentaram o maior crescimento, diferindo signific ativamente das inoculadas na altura e pesos secos da parte aérea e raízes. As plantas inoculadas com $M$. incógnita sofreram a maior redução, mostrando-se significativamente menores que as inoculadas com M. javanica. Assim, o cordão-de-frade foi considerado altamente suscetível a M.íncognita. No caso de M. javanica, embora se evidenciasse bem a suscetibilidade ao parasitismo, os danos não foram drásticos, podendo provavelmente comportar -se como tolerante em situações de infe stação menos inten sa.

Entre as leguminosas testadas, as duas espécies de fedegoso ( $C$. occidentalis $e$ C. tora) mostraram as raízes com infestações predominantemente leves e ocasionalmente moderadas. As galhas eram peque nas e visíveis, a olho nú, com certa dificuldade. Quando ocorriam ootecas externas, as galhas apresentavam o dobro do tamanho normal. As plantas dos 3 tratamentos não diferiram significativamente quanto ao crescimento, mostrando -se vigor osas e livres de sintomas de meloidoginose na parte aérea. Ambas as espécies foram considera das hospedeiros de baixa suscetibilidade, tendo interesse muito reduzido quando comparadas a outros mais favoráveis.

Finalmente a anileira, I. truxillensis, comportou-se de forma bastante semelhante às espécies de fedegoso, sofrendo infestações leves dos dois nematóides, caracterizadas pela presença de galhas pouco evidentes, esparsas ou agru padas. Não se observaram diferen- 
ças em relação ao crescimento das plantas e a leguminosa em questão foi, a exemplo das anteriores, considerada hospedeiro de baixa suscetibilidade aos parasi tos inoculados.

A eliminação de plantas daninhas consideradas tolerantes, como o capim-arroz, constitui etapa indispensável na elaboração de programas criteriosos de controle de Meloidogyne spp., principalmente através de medidas culturais. Cuidados especiais são também recomendados em relação ao cordãode-frade e ao fazendeiro, sempre que esta última espécie ocorrer em alta densidade populacional na área. As demais plantas daninhas testadas constituem hospedeiros pouco favoráveis ou altamente desfavoráveis aos parasitos, não contribuindo para aumentos em seus níveis populacionais.

\section{Com relação aos três} métodos de avaliação do grau deinfestação utilizados, praticamente se equivaleram na determinação da suscetibilidade das plantas daninhas aos nematóides inoculados, conforme indicado pelos altos coeficientes de correlação obtidos. Assim, os coeficientes (R) para as correlações entre os métodos 1 (número de galhas) e 3 (número de ootecas) para $M$. incognita e $M$. javanica foram respectivamente 0,857 e 0,862 , ambos altamente significativos. Para as correlações entre os métodos 2 (porcentagem do sistema radicular ocupada por galhas) e 3 (número de ootecas) obtiveram-se os valores 0,721 e 0,724 , respectivamente para $M$. incognita

M. javanica, também significativos.

Esses resultados, referentes às correlações entre os métodos 1 e 3 , concordam com os obtidos por Antonio \& Dall'Agnol (1983) em estudo da mesma natureza. Os coefici- entes deter minad os para a corre la ção entre os métodos 2 e 3, embora significativos, foram inferiores aos obtidos no caso dos méto dos 1 e 3 , muito prova velmente devido as dificuldades na visualização e/ou caracterização das galhas nas raízes de algumas espécies daninhas, como a trapoeraba e o capim-arroz, por exemplo.

Considera-se, portanto, os três métodos como validos para estudos deste tipo, observando-se que o método 3 é o mais seguro e conclusivo e que o método 2, embora prático, não deve ser empregado isol adame nte.

\section{LITERATURA CITADA}

Antonio, H. \& A. Dall'Agnol. Susce tibilidade de plantas daninhas a 3 espécies de nematóides, segundo 3 métodos de avaliação. In: REUNIÃO BRASILEIRA DE NEMATOLOGIA, 7, Brasília. Resumos. p.14, 1983.

Ferraz, L.C.C.B. Comportamento de diversas plantas daninhas, de ocorrência comum no Estado de São Paulo, em relação a duas espécies de nematóides das galhas: Primeira Parte. Planta Daninha, Campinas, 9: $14-20$, 1985.

Ferraz, L.C.C.B.; R.A. Pitelli \& L.E. Bendixen. An annotated bi bliography of weeds as reservoirs for organisms affecting crops in Brazil: 1. Nematodes Meloidogyne. Ohio State Univ. Res. Bul1., Wooster, no 1153, 16p., 1983.

Lorenzi, H. (ed.). Plantas Daninhas do Brasil. Nova Odessa, SP, 1ạ ed., 425pp., 1982.

Martin, G.C. Root-knot nematodes in the Federations of Rhodesia and Nyasaland. Nematologica, 
Leiden, 3: 333 - 349, 1958. Ponte, J.J.; V.J. Viana; A. Franco; R.N. Menezes \& R.C. Fonteles. Indicação de plantas imu nes à Meloidoginose: II. Triā gem entre gramineas forragei = ras. Soc. Brasil. Hematol., Pi racicaba, pub1. 6: 21-25, 198र Yassin, A.M. \& A.B. Zeidan. Rootknot nematodes in the Sudan, 1982 round-off report. In: RE-
SEARCH PLANNING CONFERENCE ON ROOT-KNOT NEMATODES, 3, Coim bra (Portugal). Proceedings, p. 131-135, 1982 .

Zem, A.C. \& L.G.E. Lordello. Nematóides associados a plantas invasoras. Anais B.S.A. "Luiz de Queiroz", Piracicaba, 33: 597 - 615, 1976. 